\title{
Evaluation of Glycemic Control Obtained from NPH Insulin in Patients Experiencing Corticosteroid-Induced Hyperglycemia
}

\author{
Megan N Hodges ${ }^{1}$, Katie B Tellor ${ }^{2 *}$ and Anastasia L Armbruster ${ }^{2}$ \\ ${ }^{1}$ Clinical Pharmacist, Virginia Mason Memorial Hospital, USA \\ ${ }^{2}$ Department of Pharmacy Practice, St. Louis College of Pharmacy, USA
}

Submission: October 28, 2017; Published: November 28, 2017

*Corresponding author: Katie B Tellor, Associate Professor of Pharmacy Practice, Department of Pharmacy Practice, St. Louis College of Pharmacy, USA, Tel: 314-996-5043; Fax: 314-996-5309; Email: Katie.tellor@stlcop.edu

\begin{abstract}
Objective: To compare the safety and efficacy of neutral protamine Hagedorn (NPH) insulin to other antidiabetic regimens in the treatment of corticosteroid-induced hyperglycemia in non-critically ill; hospitalized patients.

Methods: This retrospective cohort included patients treated with methylprednisolone or prednisone concomitantly with NPH or other antidiabetic medications for at least two days. Patients were screened for inclusion in reverse chronological order and matched based on gender; age; body mass index; steroid dose; and history of diabetes. The primary objective was mean daily blood glucose (BG). Secondary outcomes included percentage of readings between $70 \mathrm{mg} / \mathrm{dL}-180 \mathrm{mg} / \mathrm{dL}$; median daily BG; number of hypoglycemic events; daily steroid to NPH ratios; and mean weight-based dose of NPH for each $10 \mathrm{mg}$ increment of prednisone when BG readings were within goal.
\end{abstract}

Results: A total of 72 patients were included in each arm. The primary efficacy endpoint of mean daily BG ranged from $111-217 \mathrm{mg} / \mathrm{dL}$ in the control group and $163-228 \mathrm{mg} / \mathrm{dL}$ in the NPH arm; however; there were no statistically significant differences ( $>>0.05)$. Overall rates of hypoglycemia were slightly lower in the NPH group but with no statistically significant differences $(0.61 \%$ vs. $1.12 \%$; $p=0.51)$.

Conclusion: NPH; compared to other regimens; may not have an impact on achieving glycemic controlin corticosteroid-induced hyperglycemia.

Keywords: Diabetes mellitus; Corticosteroid; Hyperglycemia; Neutral protamine hagedorn

\section{Introduction}

Systemic corticosteroids are commonly used for a wide variety of medical conditions on both an inpatient and outpatient basis for the treatment of inflammation and immune suppression. Acute asthma and chronic obstructive pulmonary disease (COPD) exacerbations, rheumatoid arthritis, and organ transplant comprise just a few of the many indications. Although corticosteroids are highly efficacious, its use is limited by many serious adverse effects during acute and chronic treatment [16]. During short-course therapy, patients commonly develop hyperglycemia. Several studies have reported odds ratios from 1.5 to 2.5 for the development of new-onset diabetes relating specifically to steroid utilization [2-5]. Corticosteroids also have the potential to significantly worsen hyperglycemia in patients with a history of diabetes mellitus [1,7]. This represents a substantial health risk to patients since studies have found a correlation between hyperglycemia and decreased wound healing, increased length of stay (LOS) and mortality in hospitalized patients [8].

Several studies have been undertaken to better understand the exact mechanism of steroid-induced hyperglycemia. In patients receiving short-term therapy, skeletal muscle and hepatic cells develop reduced insulin sensitivity leading to decreased glucose uptake. During the post-prandial phase in particular, blood glucose (BG) levels are further elevated by impaired suppression of glucose production secondary to hepatic insulin resistance [6].

Insulin acts on liver, adipose tissue, and skeletal muscle to regulate metabolism of carbohydrates, fat, and protein. A cross- 
sectional review of 66 patients suggested that patients receiving $\geq 10 \mathrm{mg}$ per day of prednisolone compared to those not receiving corticosteroids experience afternoon and evening hyperglycemia despite receiving basal-bolus insulin regimens [9]. Neutral protamine Hagedorn (NPH) is a crystalline suspension of human insulin with protamine and zinc, which makes it intermediate acting insulin. Neutral protamine Hagedorn insulin produces a peak effect four to eight hours after administration with a total duration of sixteen to eighteen hours. These kinetic properties closely mirror the action of prednisone. Methylprednisolone also has a similar duration of action with a shorter onset of one to two hours [10-12]. In theory, the pharmacokinetic principles of subcutaneous NPH make it a prime candidate for the treatment of glucocorticoid induced hyperglycemia. The objective of this study is to compare NPH to other antidiabetic agents in the treatment of steroid-induced hyperglycemia.

\section{Materials and Methods}

\section{Study design}

This single-center retrospective cohort study evaluated patients at a 450-bed community hospital. The trial was approved by the hospital Institutional Review Board before data collection began. Due to the retrospective nature of the study, informed consent was not necessary. All data was obtained through electronic medical records.

Eligibility requirements included age $\geq 18$ years, concurrent treatment with methylprednisolone or prednisone with NPH insulin or other antidiabetic medications for at least two days, and steroid doses $\geq 10 \mathrm{mg}$ prednisone equivalent on day one. Patients receiving NPH for the treatment of steroid-induced hyperglycemia were included in the treatment arm and patients being treated with any other combination of antidiabetic medications were evaluated in the control arm. Patients in the NPH arm with glargine insulin as a home medication were included in the study if the glargine titration was limited to $\pm 20 \%$ during the hospitalization since a $20 \%$ reduction is recommended at admission to decrease risk of hypoglycemia and to limit confounding adjustments to the glargine during steroid titration [13]. Patients were not eligible for inclusion in the NPH treatment arm if they received any other antidiabetic medications in addition to NPH, rapid acting insulin, or glargine as described above. Oral antidiabetic agents were allowed in the control arm; however, per institutional protocols and American Diabetes Association (ADA) recommendations these agents are routinely discontinued upon admission to the hospital [14] Patients admitted with a $B G>400 \mathrm{mg} / \mathrm{dL}$, those in the intensive care unit, patients on insulin pumps, and pregnant patients were excluded. Patients were also excluded if they had less than two $B G$ readings per day or no recorded weight.

Patient characteristics were identified through queries of the hospital electronic medical record. Starting October 2014 through October 2012, all patients receiving $\geq 10 \mathrm{mg}$ of prednisone equivalent of methylprednisolone or prednisone for at least one day were consecutively screened for inclusion in reverse chronological order. After patients were identified for analysis in the NPH arm, controls were then matched by manual chart review to the NPH patients based on age, gender, body mass index (BMI) classification, steroid dose on day one, and history of diabetes.

\section{Study outcomes and definitions}

The primary outcome was the mean daily BG. Secondary outcomes included the percent of $B G$ readings within a preset goal of $70 \mathrm{mg} / \mathrm{dL}$ to $180 \mathrm{mg} / \mathrm{dL}$. All BG readings were incorporated in the analysis regardless of the patients' fasting state, thus a higher goal of $<80 \mathrm{mg} / \mathrm{dL}$ was established based on the ADA random BG recommendations for non-critically ill, hospitalized patients. The low end of this range was based on the ADA definition of hypoglycemia, which is $\mathrm{BG}<70 \mathrm{mg} / \mathrm{dL}$ [14]. Other secondary objectives included median daily BG, number of hypoglycemic and severe hypoglycemic events with and without intervention. Intervention was defined as intake of juice, oral glucose tablets or administration of glucagon or dextrose $50 \%$ water. As defined by the $\mathrm{ADA}, \mathrm{BG}<40 \mathrm{mg} / \mathrm{dL}$ is considered severe hypoglycemia. [14] Daily steroid to NPH ratios and steroid to NPH ratios on the index day were also collected. The index day was defined as the last day of steroid therapy or the day of discharge if the patient continued steroids as an outpatient. Mean weight-based dose of NPH for each $10 \mathrm{mg}$ increment of prednisone equivalent (8mg methylprednisolone) was collected for days on which all $\mathrm{BG}$ readings were within the goal range with the intention of formulating a standardized NPH protocol. Two subgroup analyses were performed on mean blood glucose to compare NPH to sliding scale insulin alone and to compare NPH to other antidiabetic regimens in patients admitted with a documented history of diabetes.

\section{Statistical analysis}

The outcomes data was analyzed to determine the glycemic control achieved with each regimen by looking at all available BG readings throughout the patients' hospitalizations excluding repeat readings within 10 minutes. Baseline characteristics and outcomes were reported using means, medians, and standard deviations for interval level data and percentages for nominal and ordinal level data. Baseline demographics and study outcomes were compared between groups using Student's t-test for continuous data and Fisher's exact or chi-square test for categorical data. A p value of $<0.05$ indicated statistical significance. All analyses were performed with IBM SPSS Statistics for Windows.

To the authors' knowledge, the only other published trials addressing this treatment regimen included a maximum of 66 patients in each arm and did not find a statistically significant difference; therefore, power was not calculated [15-17]. Based on available information, 72 patients were included in each arm. 


\section{Current Research in Diabetes \& Obesity Journal}

\section{Results}

A total of 241 patients were identified through the pharmacy informatics system for potential inclusion in the NPH arm. Of these patients, 72 were eligible based on the inclusion and exclusion criteria. Patients were well matched in regards to baseline demographics (Table 1). The only significant difference between groups was total LOS, which was significantly higher in the NPH group (6.98days vs. 4.88 days, $p=0.003$ ). However, no differences existed among indication for steroid utilization. Baseline glycemic control was similar between groups: mean BG of $186 \mathrm{mg} / \mathrm{dL}$ in the NPH group and $177 \mathrm{mg} / \mathrm{dL}$ in the control group at admission ( $\mathrm{p}=0.492)$.

Table 1: Baseline characteristics.

\begin{tabular}{|c|c|c|}
\hline & Control $(N=72)$ & NPH $(N=72)$ \\
\hline Age(years), mean $\pm S D$ & $68.7 \pm 12.1$ & $66.76 \pm 13.2$ \\
\hline LOS(days), mean $\pm S D$ & $4.88 \pm 3$ & $6.89 \pm 4.8$ \\
\hline \multicolumn{3}{|l|}{ Race, $n(\%)$} \\
\hline Caucasian & $61(84.7)$ & $60(83.3)$ \\
\hline African American & 8 11.1) & 9 12.5) \\
\hline Other & $1(1.4)$ & $2(2.8)$ \\
\hline Unknown & $2(2.8)$ & $1(1.4)$ \\
\hline \multicolumn{3}{|l|}{ Gender, n(\%) } \\
\hline Female & $42(58.3)$ & $42(58.3)$ \\
\hline Male & $30(41.7)$ & $30(41.7)$ \\
\hline Weight $(\mathrm{kg})$, mean \pm SD & $90.54 \pm 2$ & $95.33 \pm 29.1$ \\
\hline History of DM, n(\%) & $59(81.9)$ & $59(81.9)$ \\
\hline $\begin{array}{l}\text { Home insulin therapy, } \\
\mathrm{n}(\%)\end{array}$ & $27(37.5)$ & $38(52.8)$ \\
\hline $\begin{array}{l}\text { Home steroid therapy, } \\
\mathrm{n}(\%)\end{array}$ & $24(33.3)$ & $30(41.7)$ \\
\hline $\begin{array}{l}\text { Day } 1 \text { prednisone } \\
\text { equivalent }(\mathrm{mg}) \text {, mean } \pm S D\end{array}$ & $109.4 \pm 55.3$ & $109 \pm 155.8$ \\
\hline
\end{tabular}

*There were no significant differences between the two groups except for LOS $(p=0.003)$

The primary efficacy endpoint of mean daily BG ranged from $111-217 \mathrm{mg} / \mathrm{dL}$ in the control group and $164-228 \mathrm{mg} / \mathrm{dL}$ in the NPH arm; however, no statistically significant differences were detected for any day (Figure 1) \& (Table 2). The results on the index day (Table 3) showed numerically though not statistically improved glycemic control for the control group compared with the NPH arm with a mean BG of $195 \mathrm{mg} / \mathrm{dL}$ for the NPH group and $179 \mathrm{mg} / \mathrm{dL}$ for the control group $(\mathrm{p}=0.135)$.

In regards to efficacy, the only statistically significant difference found was in the percent of BG readings between 70-
$180 \mathrm{mg} / \mathrm{dL}$ for day 1 in favor of the control arm (41.9\%vs.28.1\%, $\mathrm{p}=0.01$ ) (Table 4). No trends were observed for the steroid: NPH ratios or weight-based NPH doses. Consistent glycemic control was achieved faster in the control arm; mean daily BG readings were $<180 \mathrm{mg} / \mathrm{dL}$ starting on day 5 compared to day 10 in the NPH arm (Figure 1). In contrast to a previous study, the NPH arm received a significantly higher total daily insulin dose on the index day compared to the control arm $(0.37 \mathrm{unit} / \mathrm{kg}$ vs. 0.21 unit $/ \mathrm{kg}, \mathrm{p}=0.002$ ). However, these differing results are likely accounted for by the inclusion of glargine insulin in the NPH arm [15].

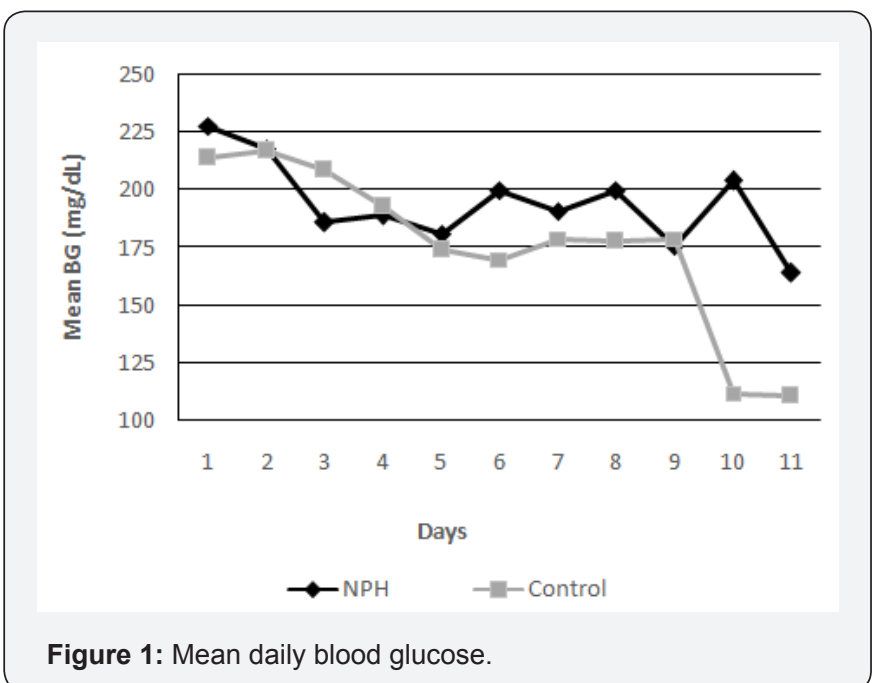

Table 2: Mean daily blood glucose (mg/dL).

\begin{tabular}{|c|c|c|c|c|c|}
\hline Days & $\mathbf{N P H}$ & $\mathbf{n}$ & $\mathbf{C o n t r o l}$ & $\mathbf{n}$ & $\mathbf{p}$ \\
\hline 1 & $228 \pm 66$ & 72 & $214 \pm 71$ & 72 & 0.234 \\
\hline 2 & $218 \pm 69$ & 72 & $217 \pm 77$ & 72 & 0.923 \\
\hline 3 & $186 \pm 64$ & 50 & $209 \pm 68$ & 48 & 0.087 \\
\hline 4 & $189 \pm 58$ & 37 & $193 \pm 84$ & 33 & 0.826 \\
\hline 5 & $181 \pm 67$ & 20 & $174 \pm 80$ & 25 & 0.73 \\
\hline 6 & $200 \pm 81$ & 15 & $170 \pm 62$ & 18 & 0.246 \\
\hline 7 & $191 \pm 60$ & 9 & $179 \pm 76$ & 11 & 0.705 \\
\hline 8 & $200 \pm 67$ & 7 & $178 \pm 25$ & 8 & 0.438 \\
\hline 10 & $176 \pm 36$ & 6 & $179 \pm 52$ & 7 & 0.91 \\
\hline 11 & $164 \pm 25$ & 2 & 111 & 1 & - \\
\hline
\end{tabular}




\section{Current Research in Diabetes \& Obesity Journal}

Table 3: Index daya.

\begin{tabular}{|c|c|c|c|}
\hline & NPH (n=72) & Control (n=72) & p-Value \\
\hline $\begin{array}{c}\text { Mean blood } \\
\text { glucose, mg/dL }\end{array}$ & $195 \pm 69$ & $179 \pm 51$ & 0.135 \\
\hline $\begin{array}{c}\text { Median blood } \\
\text { glucose, mg/dL }\end{array}$ & $189 \pm 75$ & $173 \pm 49$ & 0.13 \\
\hline $\begin{array}{c}\text { Total daily insulin } \\
\text { dose, units/kg }\end{array}$ & $0.37 \pm 0.34$ & $0.21 \pm 0.25$ & 0.002 \\
\hline $\begin{array}{c}\text { Total prednisone } \\
\text { equivalent, mg }\end{array}$ & $56.6 \pm 78.3$ & $51.7 \pm 53.5$ & 0.665 \\
\hline
\end{tabular}

aData presented as mean \pm standard deviation.

Table 4: Percent blood glucose $70-180 \mathrm{mg} / \mathrm{dl}$.

\begin{tabular}{|c|c|c|c|}
\hline Day & NPH & Control & p Value \\
\hline 1 & $28.1 \%$ & $41.9 \%$ & 0.01 \\
\hline 2 & $39.6 \%$ & $43.1 \%$ & 0.569 \\
\hline 3 & $51.8 \%$ & $42.3 \%$ & 0.158 \\
\hline 4 & $50.7 \%$ & $49.5 \%$ & 0.893 \\
\hline 5 & $61.2 \%$ & $40 \%$ & 0.52 \\
\hline 6 & $52.8 \%$ & $62.1 \%$ & 0.451 \\
\hline 7 & $52 \%$ & $48.7 \%$ & 0.838 \\
\hline 8 & $38.6 \%$ & $49 \%$ & 0.496 \\
\hline 9 & $55.6 \%$ & $56 \%$ & 0.978 \\
\hline
\end{tabular}

Glycemic control was similar in both subgroup analyses (patients with a history of diabetes and those receiving only slide scale insulin compared to NPH) (data not shown). In patients with a documented history of diabetes, the mean BG on the index day was $197 \mathrm{mg} / \mathrm{dL}$ in the NPH arm compared to $185 \mathrm{mg} / \mathrm{dL}$ in the control arm $(\mathrm{p}=0.313)$. When comparing NPH and sliding scale insulin versus sliding scale insulin alone, BG on the index day was $187 \mathrm{mg} / \mathrm{dL}$ in the NPH group and $174 \mathrm{mg} / \mathrm{dL}$ in the sliding scale insulin group $(\mathrm{p}=0.246)$.

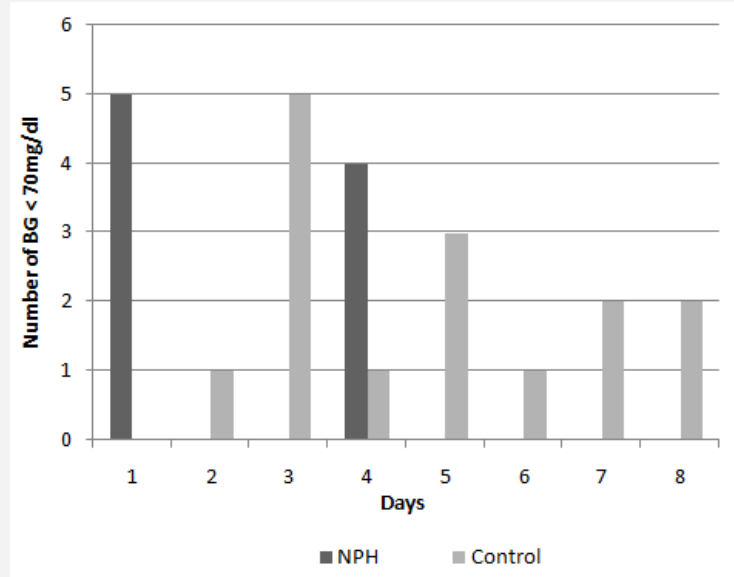

Figure 2: Hypoglycemic events.
Overall, the incidence of hypoglycemia was low in both arms, with more events occurring in the control arm (Figure 2). A total of $9(0.61 \%)$ hypoglycemic episodes occurred in the NPH arm and $15(1.12 \%)$ in the control arm $(p=0.51)$. Only one episode of severe hypoglycemia was noted in the control arm.

\section{Discussion}

When interpreting these results, it is important to note that the number of patients evaluated dropped considerably each consecutive day. By day eleven, only two patients remained in the NPH arm compared to one patient in the control arm. Although daily trends are important to consider, the results on the index day may provide the most insight on glycemic control.

Several limitations exist within this study. Due to the retrospective design, there is also potential for data extraction errors and chart documentation errors. Another limitation is the lack of standardized NPH dosing at this institution. The doses prescribed varied greatly between patients, and the majority of weight-based NPH doses were much lower than other institution protocol recommendations [1,8-15]. Overall glycemic control was also relatively poor in both groups compared to previous studies. This could be partly due to higher daily steroid doses and lack of Diabetes Management Services [15]. Lastly, patients in the NPH group had a significantly longer LOS compared to the control group, which could have resulted in worse overall BG control with increased time of steroid exposure. However, there were no measurements to determine severity of illness to help explain the extended LOS. Although this study was conducted at a single community hospital with a limited sample size, it is the largest study to evaluate this topic.

Despite a lack of evidence, several institutions have implemented protocols for the use of weight-based NPH dosing for hyperglycemic patients treated with steroids. The doses usually range from 0.1 units $/ \mathrm{kg}$ to 0.5 units $/ \mathrm{kg}$ depending on steroid doses [1,8-15]. One retrospective cohort of 120 patients found no difference between NPH versus glargine to control steroid-induced hyperglycemia in patients with type 2 diabetes [15]. A randomized control trial of 50 patients evaluated whether an NPH-based insulin regimen is safer and more effective than a glargine-based regimen in hospitalized adults with prednisolone-induced hyperglycemia. The initial daily insulin dose was 0.5 units $/ \mathrm{kg}$ or $130 \%$ of the current daily insulin dose. No differences in either outcome was observed [16]. Another randomized control trial of 53 patients examining glargine versus NPH in type II diabetics with respiratory disease and glucocorticoid induced hyperglycemia yielded similar results [17]. This current trial included patients regardless of their diabetes history or steroid indication. Despite the similarity in pharmacokinetic profiles between corticosteroids and NPH, this approach may not offer better glycemic coverage in steroidinduced hyperglycemia over other regimens as shown in this trial and in the studies by Dhital et al. [15], Ruiz de Adana et al. [17], \& 
Radhakutty et al. [16]. Additional large, randomized-controlled trials are warranted to further help direct future evidence-based treatment strategies for steroid-induced hyperglycemia.

\section{Conclusion}

Based on the results of this study, no conclusions can be determined about the efficacy of NPH insulin for corticosteroidinduced hyperglycemia. Patients receiving standard care (control group) appeared to have better glycemic control over patients in the NPH arm; however, the resulting differences were not statistically significant and hampered by small sample size.

\section{References}

1. Clore J, Thurby Hay L (2009) Glucocorticoid-induced hyperglycemia. Endocr Pract 15(5): 469-474.

2. Gulliford M, Charlton J, Latinovic R (2006) Risk of diabetes associated with prescribed glucocorticoids in a large population. Diabetes Care 29: $2778-2729$

3. Gurwitz JH, Bohn RL, Glynn RJ, Monane M, Mogun H, et al. (1994) Glucocorticoids and the risk for initiation of hypoglycemic therapy. Arch Intern Med. 154(1): 97-101

4. Conn H, Poynard T (1994) Corticosteroids and peptic ulcer: metaanalysis of adverse events during steroid therapy. J Intern Med 236(6): 619-632.

5. Blackburn D, Hux J, Mamdani M (2002) Quantification of the risk if corticosteroid-induced diabetes mellitus among the elderly. J Gen Intern Med 17(9): 717-720.

6. Van Raalte DH, Ouwens DM, Diamant M (2009) Novel insights into glucocorticoid-mediated daibetogenic effects: towards expansion of therapeutic options? Eur J Clin Invest 39(2): 81-93.

7. Baldwin D, Apel J (2013) Management of hyperglycemia in hospitalized patients with renal insufficiency or steroid-induced diabetes. Curr Diab Rep 13(1): 114-120.
8. Umpierrez G, Isaacs S, Bazargan N, Xiangdong Y, Leonard MT, et al. (2002) Hyperglycemia: an independent marker of in-hospital mortality in patients with undiagnosed diabetes. The Journal of Clinical Endocrinology \& Metabolism 87(3): 978-982.

9. Burt MG, Drake SM, Aguilar Loza NR, Esterman A, Stranks SN, et al. (2015) Efficacy of a basal bolus insulin protocol to treat prednisoloneinduced hyperglycaemia in hospitalised patients. Intern Med J 45(3): 261-266.

10. Triplitt CL, Repas T, Alvarez C (2005) Chapter 57. Diabetes Mellitus. In: DiPiro JT, Talbert RL, Yee GC, Matzke GR, Wells BG, et al. (Eds.), Pharmacotherapy: A Pathophysiologic Approach. (6 $6^{\text {th }}$ edn), MCGrawHill, USA.

11. Magee MH, Blum RA, Lates CD, Jusko WJ (2001) Prednisolone pharmacokinetics and pharmacodynamics in relation to sex and race. J Clin Pharmacol 41(11): 1180-1194.

12. (2017) Lexicomp Online, Lexi-Comp, Inc, USA.

13. Tobin G, Rometo D (2012) Inpatient management of diabetes. In: McGill J, Clutter W, Baranski T, Katherine H (Eds.), The Washington Manual: Endocrinology Subspecialty Consult, ( $3^{\text {rd }}$ edn), UK, pp. 286-297.

14. (2016) American Diabetes Association. Standards of medical care in diabetes. Diabetes care in the hospital. 39(Suppl 1): S99-S104.

15. Dhital S, Shenker Y, Meredith M, Davis DB (2012) A retrospective study comparing neutral protamine hagedorn insulin with glargine as basal therapy in prednisone-associated diabetes mellitus in hospitalized patients. Endocr Pract 18(5): 712-719.

16. Radhakutty A, Stranks JL, Mangelsdorf BL, Drake SM, Roberts GW et al. (2017) Treatment of prednisolone-induced hyperglycaemia in hospitalized patients: Insights from a randomized, controlled study. Diabetes Obes Metab 19(4): 571-578.

17. Ruiz de Adana MS, Colomo N, Maldonado Araque C, Fontalba MI, Linares F, et al. (2015) Randomized clinical trial of the efficacy and safety of insulin glargine vs. NPH insulin as basal insulin for the treatment of glucocorticoid induced hyperglycemia using continuous glucose monitoring in hospitalized patients with type 2 diabetes and respiratory disease. Diabetes Res Clin Pract 110(2): 158-165.

\section{Your next submission with Juniper Publishers will reach you the below assets}

